Research Article

\title{
Experimental Hazardous Rock Block Stability Assessment Based on Vibration Feature Parameters
}

\author{
Zheng He, ${ }^{1}$ Mowen Xie ${ }^{D},{ }^{1}$ Zhengjun Huang, ${ }^{1}$ Yuan Li $\mathbb{D},{ }^{1}$ Zhili Sui, ${ }^{2}$ Yongdu Lu, ${ }^{1}$ \\ and Andrei M. Golosov ${ }^{3}$ \\ ${ }^{1}$ School of Civil and Resource Engineering, University of Science and Technology Beijing, Beijing 100083, China \\ ${ }^{2}$ School of Urban Construction, Beijing City University, Beijing 100083, China \\ ${ }^{3}$ School of Engineering, Far Eastern Federal University, Vladivostok 690090, Russia \\ Correspondence should be addressed to Mowen Xie; mowenxie@126.com
}

Received 4 July 2020; Revised 9 October 2020; Accepted 21 October 2020; Published 21 November 2020

Academic Editor: Fengqiang Gong

Copyright (c) 2020 Zheng He et al. This is an open access article distributed under the Creative Commons Attribution License, which permits unrestricted use, distribution, and reproduction in any medium, provided the original work is properly cited.

This paper explores a new approach for assessing the stability of a hazardous rock block on a slope using vibration feature parameters. A physical model experiment is designed in which a thermally sensitive material is incorporated into the potential failure plane of the hazardous rock, and the complete process of hazardous rock collapse caused by strength deterioration is simulated by means of constant-temperature heat transfer. Moreover, the vibration response of the hazardous rock is monitored in real time by laser vibrometry. The experimental results show that five vibration feature parameters, including the mean frequency, the center frequency, the peak frequency, the mean frequency standard deviation, and the root mean square frequency, are well-correlated with rock stability. Furthermore, through principal component analysis, the five vibration feature parameters are synthesized into a principal component factor (PCF) as a representative assessment parameter. The results of the analysis demonstrate that the variation in the PCF exhibits three characteristic stages, i.e., "stationary-deviation-acceleration," and can effectively identify the stability evolution trend and collapse precursor behavior of hazardous rock block.

\section{Introduction}

Hazardous rock, located on a steep slope and surrounded by weak failure planes, is a rock block with little stability (Figure 1). The collapse of rocks is a significant natural hazard in mountainous areas. In most cases, it is difficult to predict the stability of the rock block and to implement effective mitigation measures due to the abruptness and destructivity of the collapse. Some studies have shown that the mechanical stability of a rock slope is greatly affected by the deformation and strength characteristics of the potential failure plane in the rock mass $[1,2]$. Additionally, strength deterioration of a potential failure plane caused by weathering, earthquake or heavy precipitation is the root cause of rock collapse $[3,4]$.

Generally, the stability assessment of rock blocks is based on empirical judgments gained by visual inspection of rock mass structures. However, it is difficult to quantitatively assess stability with visual inspection. The instability and failure of the rock slope is a progressive process [5], and the precursory indicators that existed before the rupture enable the assessment of the stability and to forecast the failure [6]. Many researchers have reported by using extensometer, photogrammetry, global positioning system (GPS), light detection and ranging (LiDAR), ground-based interferometry synthetic aperture radar (GBInSAR), and other technical approaches to observe displacement (or strain) to locate hazardous rocks [7-13]; however, in general, hazardous rock collapses at low strain and tertiary creep develop very rapidly [14], which makes it difficult to use displacement (or strain) to monitor the strength deterioration in a rock mass and to predict its tendency towards stability development [15].

In recent years, damage identification theory has been developed. This theory is based on measuring the vibration response of structures and extracting vibration feature 


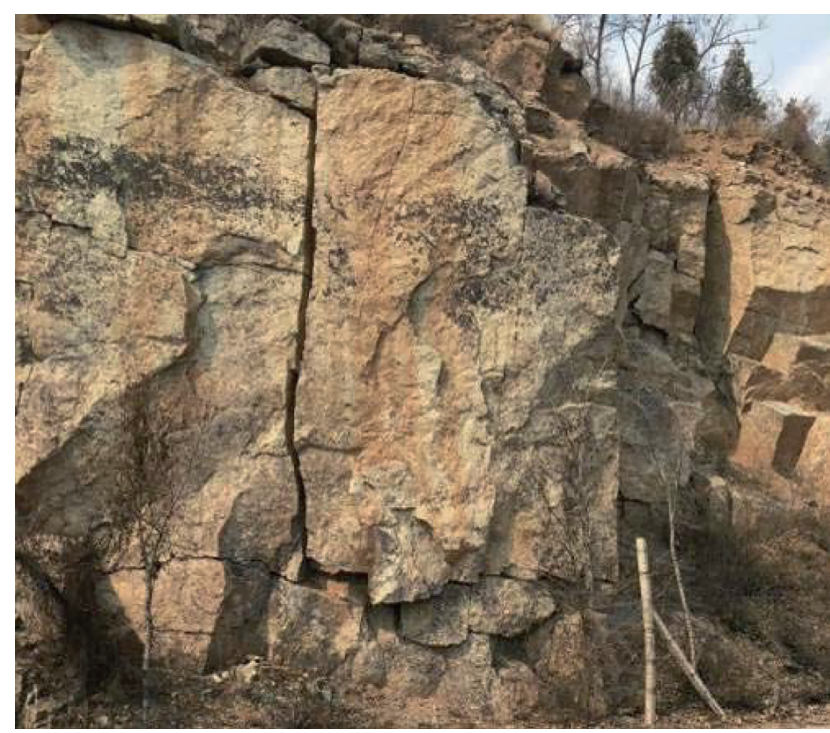

FIgURE 1: Typical hazardous rock block structure.

parameters to identify the degree of damage [16]. Many researchers have reported assessing the probability of rock failure by measuring vibration feature parameters using sensors installed into the hazardous rock block [17-20]. Additionally, the laser Doppler vibrometer (LDV) has been proven to measure vibration response quickly and accurately over long distances both experimentally and practically $[21,22]$. Laser vibrometry is effective for identifying the strength deterioration of rock blocks on slopes. Ma et al. [23] conducted a concrete block vibration monitoring test using LDV and found that the tendency of the dominant frequency is consistent with the positive correlation between the block mechanical stability and the adhesion area by changing the bonding area between the concrete block and the concrete pedestal. Du et al. [24] bonded the toughened glass block with the freezing method and measured its vibration signal during the process from freezing to thawing using LDV. They found that the fundamental natural frequency decreased when the cohesion of the potential sliding plane gradually weakened. Jia et al. [25] monitored the fundamental natural frequency of hazardous rock onsite and calculated the actual safety factor of the rock mass by the mass-spring model. Thus, frequency response monitoring is a practical and reasonable method to evaluate the stability of hazardous rock block.

In this paper, we explore a new method of assessing the stability of a hazardous rock block on a slope using vibration feature parameters. A physical model experiment is designed in which a thermally sensitive material is incorporated into the potential failure plane of hazardous rock, and the complete process of hazardous rock collapse caused by strength deterioration is simulated by means of constanttemperature heat transfer. Moreover, the vibration response of the hazardous rock is monitored in real time by laser vibrometry to obtain the vibration feature parameters that are strongly related to the stability of the rock block and to analyze its evolution law.

\section{Theoretical Model}

From the perspective of statics, the failure of the dangerous rock block is due to insufficient tensile (or shear) resistance at the potential failure plane. The hazardous rock block is regarded as a structure, and the resistance to maintain its equilibrium is provided by the structural stiffness of the potential failure plane. If the change of resistance stiffness can be accurately judged, the stability development trend of the rock block can be evaluated, but this change is difficult to obtain by statics. For a structural dynamic analysis, we use a damping spring to simulate the stiffness characteristics of the potential failure plane $[26,27]$, assuming that the rock block is a rigid body, the slope is a fixed body, and the deformation of the potential failure plane is linear elastic deformation within the amplitude range. The hazardous rock mass can thus be regarded as a dynamic system, and the main vibration mode is a swing around a fixed base point [28]. The dynamic model is shown in Figure 2.

In this analysis model, the rock block and the stable part compose a single-degree-of-freedom dynamic system. When the damping coefficient is ignored, the differential equation of the dynamic system can be expressed as

$$
J_{o} \ddot{\theta}+\frac{k l^{2}}{4} \theta=0
$$

The natural frequency can be expressed as

$$
\begin{aligned}
& f=\frac{1}{4 \pi} \sqrt{\frac{E l^{3}}{d J_{o}}}, \\
& J_{o}=\rho m n\left[\frac{\left(m^{2}+n^{2}\right)}{12}+a^{2}+b^{2}\right],
\end{aligned}
$$

where $f$ is the natural frequency of the dynamic system $(\mathrm{Hz})$, $J_{0}$ is the moment of inertia of the rock block around point $O$ $(\mathrm{kg} \cdot \mathrm{m}), \rho$ is the density of the rock block $\left(\mathrm{kg} / \mathrm{m}^{3}\right)$, and $E$ is the elastic modulus of the potential failure plane $(\mathrm{Pa})$.

As shown in equations (1)-(3), the natural frequency of the dynamic system can be calculated from the rotary inertia of the rock and the stiffness and size of the potential failure plane. Here, we consider that the stiffness and the size of the potential failure plane are closely related to the rock block stability $[1,29]$ and that the size and density distribution of the rock block are generally unchanged; therefore, in theory, the stability of the rock block can be characterized by its natural frequency. In practical applications, we generally measure the vibration response to analyze the natural frequency characteristic of the rock block [30]. Hence, in this study, we examine the vibration response feature parameters 


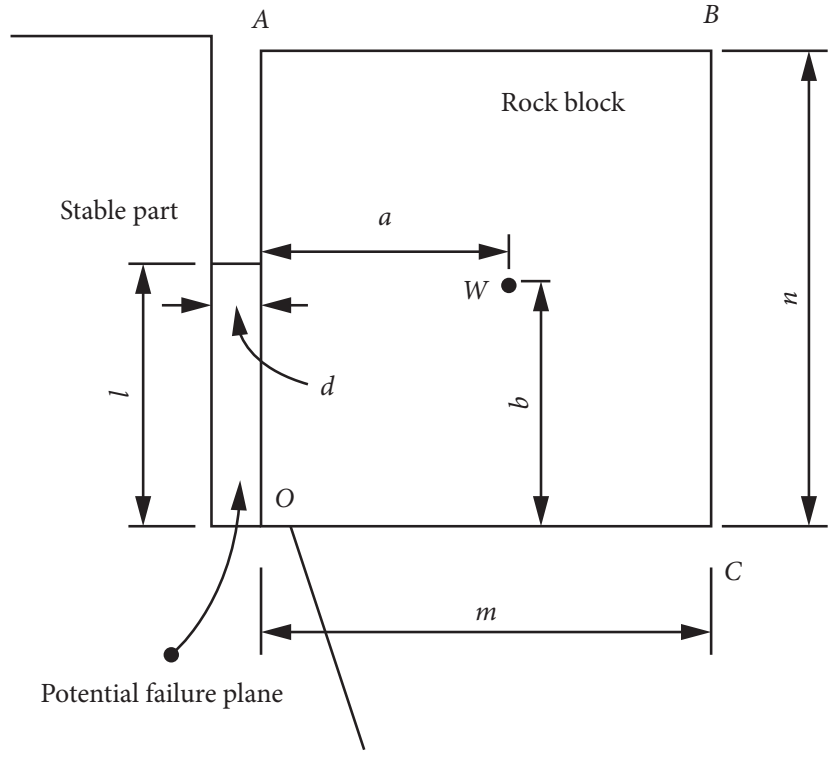

(a)

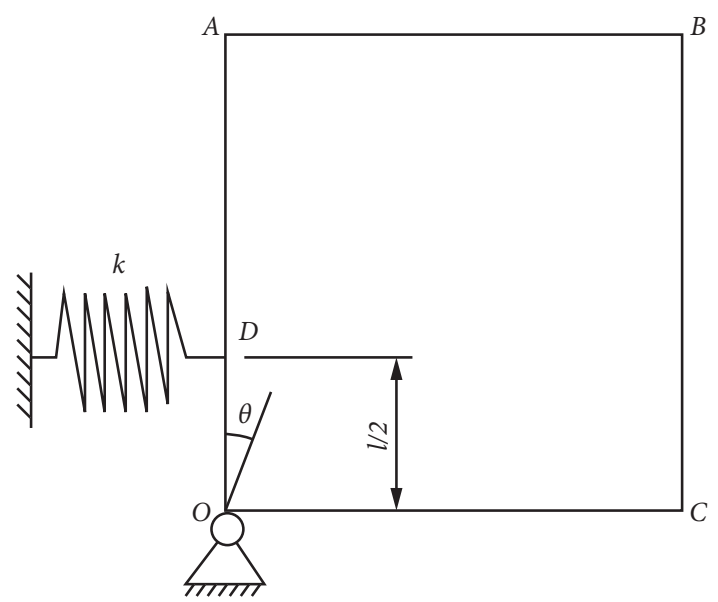

(b)

FIGURE 2: Structural model of a hazardous rock block and its dynamic analysis model. (a) Structural model. (b) Dynamic model. Here, (a) and (b) are the position coordinates of the rock center of mass (point (W)), (m) and (n) represent the size of the rock, (l) and (d) represent the size of the potential failure plane, $(\mathrm{k})$ is the equivalent stiffness of the potential failure plane, and $\theta$ is the microrotation angle under excitation.

in the frequency domain to characterize the stability of the rock block.

\section{Experimental Method}

3.1. Experimental Model. In this experiment, a concrete block is used to represent the unstable block. The potential failure plane is constructed of a material whose strength is heat-sensitive: sand and gypsum as the aggregate and paraffin as the gelling agent [31]. An electric heating element is embedded in the material to control the degree of damage to the potential failure plane. The heat-sensitive material is used to bond the concrete block and the stable slope. As the heating element heats up, the strength (stiffness) of the material of the potential failure plane gradually deteriorates. Simultaneously, an LDV is used to record the vibration signal of the concrete block under the excitation. Figure 3 shows a schematic of the experimental model. Table 1 shows the size and weight of the experimental material.

3.2. Experimental Equipment. The experimental equipment includes an LDV, an accelerometer, an electric heating element, an infrared thermal imager, and a vibration exciter. An RSV-150 LDV produced by Polytec, Germany, is applied to measure the surface vibration and displacement of the block, as shown in Figure 4(a), with a frequency measurement range of $0-25 \mathrm{kHz}$, speed resolution of $<0.5 \mu \mathrm{m} / \mathrm{s} /$ $\sqrt{ } \mathrm{Hz}$, and displacement resolution of $0.3 \mathrm{~nm}$. An $\mathrm{H} 36$ infrared camera produced by Hikvision, China, is applied to measure the temperature variation in the potential failure plane, as shown in Figure 4(b) with a temperature measurement range of $-20-400^{\circ} \mathrm{C}$, a temperature measurement accuracy of $\pm 2^{\circ} \mathrm{C}$, and a resolution of $0.1^{\circ} \mathrm{C}$.

3.3. Experimental Advantage. In this experiment, the temperature of the potential failure plane is varied to control the strength of the concrete block. The associated experimental advantages are (1) the test can simulate the entire process of rock block collapse under the influence of gravity without human external intervention; (2) the concrete block can be controlled to different stable states; and (3) the test has good operability and repeatability.

\section{Experiment I: Determination of Vibration Feature Parameters}

4.1. Experimental and Analytical Procedures. To determine the vibration feature parameters that characterize the stability of the block, we adjust the electric heating element to different fixed temperatures and use the infrared thermal imager to monitor the thermal conduction process of the potential failure plane. When the temperature is constant, we measure the vibration response of the concrete block under impact excitation by laser vibrometry and the stability safety factor by a loading test.

The experimental simplified stability calculation model is shown in Figure 5. When the concrete block is loaded to the equilibrium limit, the stability safety factor is defined as the ratio of the overturning moment and the maximum resistance moment of the block. The stability safety factor of the block can be expressed as follows: 


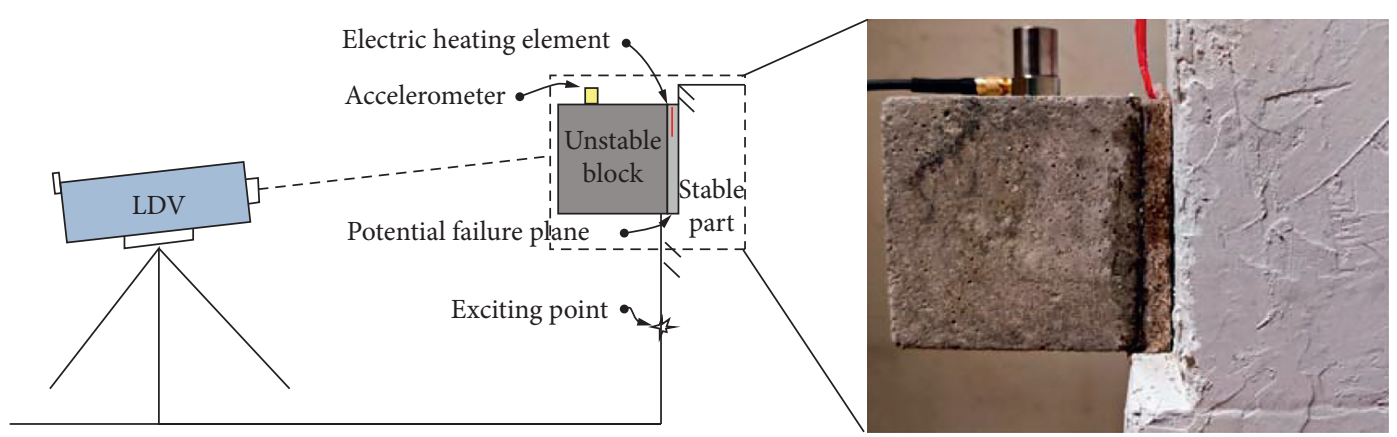

Figure 3: Experimental model.

TABLe 1: Size and weight of the materials.

\begin{tabular}{|c|c|c|c|c|}
\hline \multirow{2}{*}{ Material } & \multicolumn{3}{|c|}{ Size $(\mathrm{cm})$} & \multirow{2}{*}{ Mass (g) } \\
\hline & Length & Width & Height & \\
\hline Unstable rock & 7.1 & 7.1 & 7.1 & 788.9 \\
\hline Potential failure plane & 7.1 & 0.5 & 7.1 & 29.7 \\
\hline
\end{tabular}

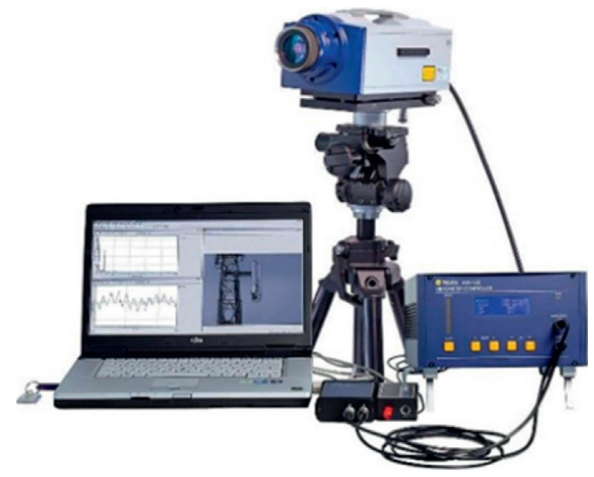

(a)

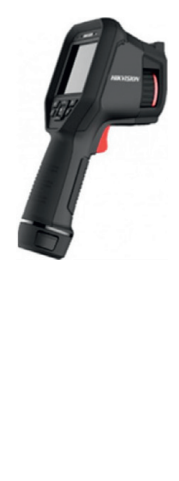

(b)

FIgURE 4: Experimental instruments: (a) laser Doppler vibrometer; (b) infrared thermal imager.

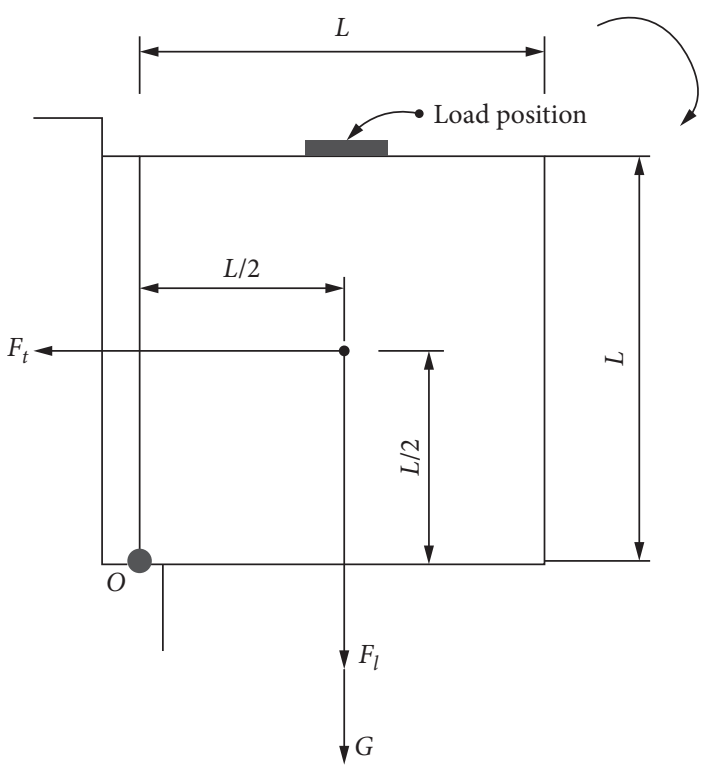

FIGURE 5: Stability calculation model of the concrete block. 


$$
f_{s}=\frac{F_{t}}{G}=\frac{G+F_{l}}{G},
$$

where $f_{s}$ is the stability safety factor of the concrete block, $G$ is the block weight $(\mathrm{N}), F_{t}$ is the tensile resistance $(\mathrm{N})$, and $F_{l}$ is the vertical limit load $(\mathrm{N})$.

Under a consistent experimental method, five temperature states were measured, including $15^{\circ} \mathrm{C}, 26^{\circ} \mathrm{C}, 35^{\circ} \mathrm{C}, 44^{\circ} \mathrm{C}$, and $48^{\circ} \mathrm{C}$. The infrared thermal imaging of the concrete blocks is shown in Figure 6.

4.2. Experimental Results. The experimental results show that, as the temperature of the potential failure plane increases, its strength decreases, until the block collapses (the failure temperature is $53^{\circ} \mathrm{C}$ ). Figure 7 shows the correlation between the safety factor calculated by equation (4) and the temperature of the potential failure plane. The fitting formula of the safety factor is as follows:

$$
f_{s}=3.585-0.194 \exp \left(\frac{T}{20.383}\right),
$$

where $f_{s}$ is the stability safety factor of the concrete block and $T$ is the temperature of the potential failure plane $\left({ }^{\circ} \mathrm{C}\right)$.

In addition, the spectrum response curve is obtained by smoothing, denoising, and fast Fourier transformation of the vibration response data, as shown in Figure 8. As the temperature of the potential failure surface rises, the magnitude and position of the spectrum curve change significantly, indicating that the vibration characteristics of the concrete block have changed.

Furthermore, using statistical analysis, five vibration feature parameters to characterize the stability of the block are obtained, including the mean frequency (P1), the center frequency $(\mathrm{P} 2)$, the root mean square frequency (P3), the peak frequency $(\mathrm{P} 4)$, and the mean frequency standard deviation (P5). Specific explanations of the parameters are shown in Table 2. Parameter P1 is the vibration magnitude in the frequency domain. Parameters P2-P4 describe the convergence of the spectrum power. Parameter P5 shows the position change in the main frequencies [32].

Table 3 shows a list of vibration feature parameters in different stable states. Figure 9 shows the correlations between the vibration feature parameters and the concrete block stabilities. During progression from state 1 to state 5, the block stability has a significant negative correlation with P1 and P5, which shows that the magnitude and constringency of the vibration frequency domain increase; the block stability has a significant positive correlation with $\mathrm{P} 2-\mathrm{P} 4$, which shows that the main frequencies gradually decrease. In addition, the data show that using a single parameter for assessment is susceptible to erroneous evaluation, such as the peak frequency commonly used by researchers [23-25], which has an abnormal trend change in state 3 . For this reason, we use multiple parameters to assess the stability evolution trend.

\section{Experiment II: Assessment of the Stability Evolution Trend}

5.1. Experimental and Analytical Procedures. In experiment II, a constant temperature $\left(53^{\circ} \mathrm{C}\right)$ heat transfer condition is set. As heat transfer progresses between the electric heating element and the potential failure plane, the stability of the concrete block continues to decrease, and the block ultimately collapses. The experiment records the dynamic changes in displacement, vibration signal, and temperature. To incorporate the variation characteristics of the five kinds of vibration feature parameters as much as possible, principal component analysis is used to obtain the principal component factor (PCF) as a representative assessment parameter. Furthermore, the stage characteristics of PCF variation and relevance with the stability evolution trend are analyzed.

5.2. Experimental Results and Discussion. In this experiment, 40 vibration acceleration response samples are obtained, and the initial vibration feature parameter data matrix $X=\left(x_{i j}\right)_{n \times p}$ is calculated, where $i=1,2, \ldots, n, n=40$, representing 40 samples; $j=1,2, \ldots, p, p=5$, representing 5 parameters; and $x_{i j}$ represents the $j$-th parameter value of the $i$-th sample.

The scree plot obtained by principal component analysis is shown in Figure 10. The abscissa is the component number, and the ordinate is the eigenvalue. The eigenvalue of the first principal component is larger $(>1)$ than the others, and the variance contribution reached $92.717 \%$, indicating that most of the information of the vibration feature parameters is represented. Therefore, the load matrix $L$ of the first principal component is adopted as the weight of each vibration feature parameter as follows:

$$
L=[-0.455,0.448,0.447,0.449,-0.435]^{T} .
$$

Therefore, the PCF of the vibration feature parameters can be expressed as follows:

$$
\mathrm{PCF}=\frac{x_{i j}-\bar{x}_{j}}{S_{j}} \cdot L,
$$

where $\bar{x}_{j}=\left(\sum_{i=1}^{n} x_{i j} / n\right)$ and $S_{j}=\sqrt{\left(\sum_{i=1}^{n}\left(x_{i j}-\bar{x}_{j}\right)^{2} / n\right)}$.

In addition, the safety factor of the concrete block at different times is calculated by temperature data and equation (5).

Figure 11 shows the typical time histories of the safety factor, the displacement, the PCF, and the PCF variation rate. In the experiment, the unstable block collapsed approximately $738 \mathrm{~s}$ after the potential failure plane was heated. The displacement responded only minimally for a long period of time, and an abnormal change in the submillimeter level occurred only $5 \mathrm{~s}$ before collapse. In contrast, the evolution of the PCF featured obvious characteristic stages. In the initial "stationary" phase, the 


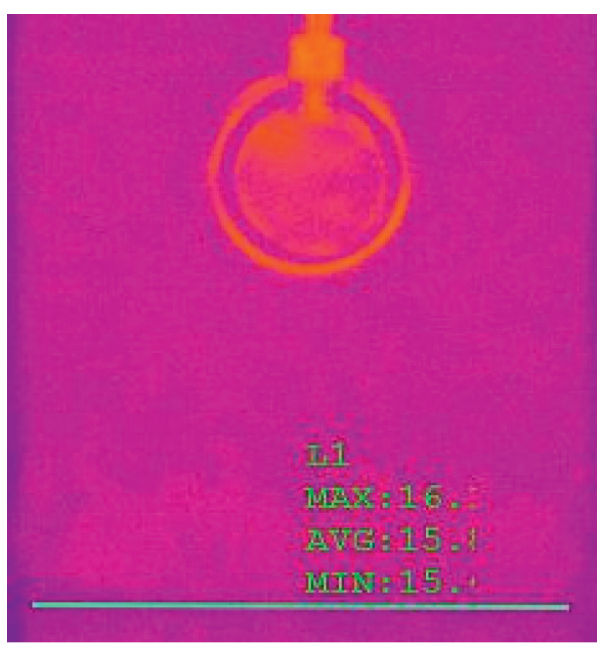

(a)

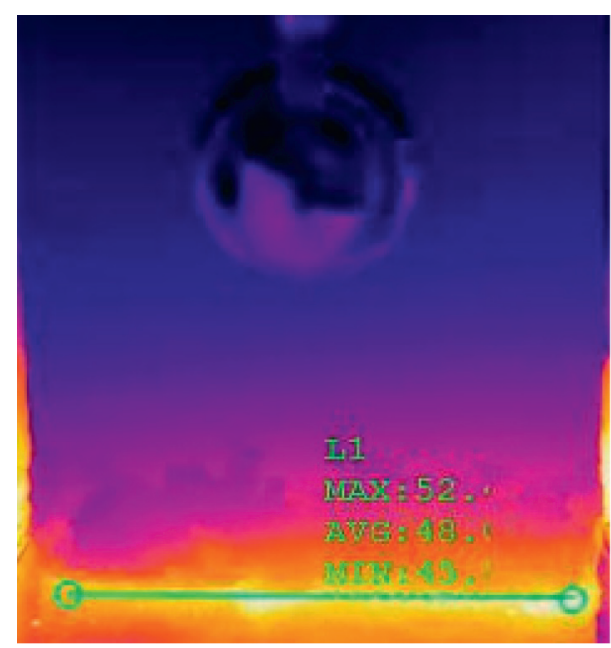

(b)

FIGURE 6: Infrared thermal imaging of the concrete block: (a) ambient temperature $\left(15^{\circ} \mathrm{C}\right)$; (b) heating temperature $\left(48^{\circ} \mathrm{C}\right)$.

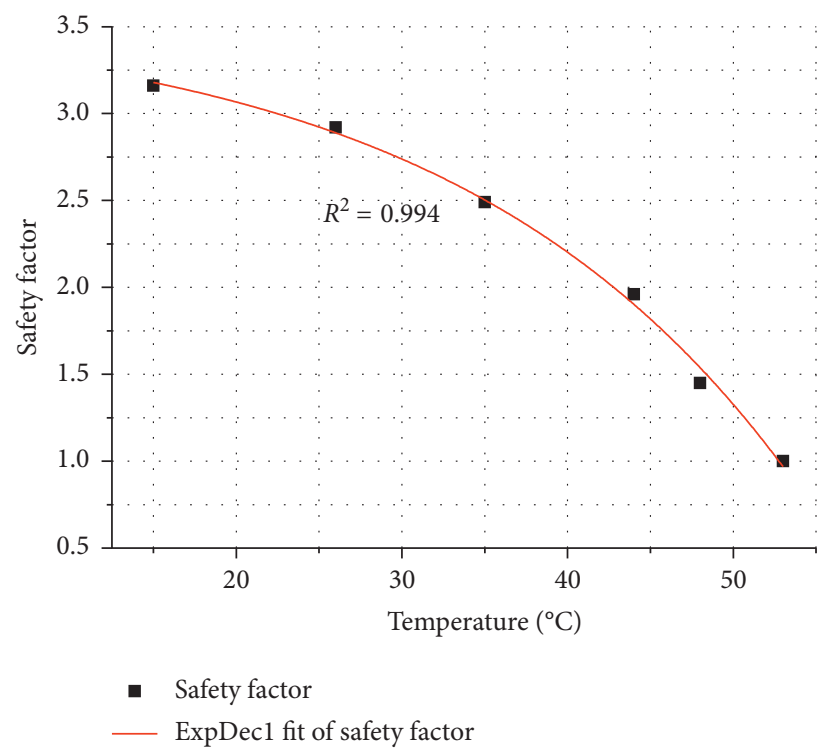

FiguRE 7: Relation between the stability safety factor and temperature.

variation rate of the PCF was almost 0 , and the safety factor of the block also remained constant. With the strength deterioration of the unstable block, the safety factor decreased slowly after 140 s, and the PCF exhibited "deviation," decreasing at a nearly uniform variation rate. At $400 \mathrm{~s}$, the PCF entered the "acceleration" phase, its variation rate increased, and the decrease in the safety factor also accelerated. At $700 \mathrm{~s}$, the PCF exhibited an abnormal sudden drop, and the block was close to collapse. The same trend was obtained by repeated tests. The experimental results show that the PCF can effectively characterize the stability evolution trend of unstable blocks and that its sensitivity to strength deterioration is better than that of the displacement. Additionally, the abnormal sudden decrease of the PCF in the acceleration phase is a precursor to collapse.

\section{Discussion}

The collapse disaster from a rock block is a process of evolution with time, during which the state of the rock block changes from stability, to damage, to instability. At present, field monitoring data are mainly used to evaluate the safety status of rock blocks, and the effective monitoring indicators should correlate well with the stability of rock blocks. The conventional monitoring and early warning information based on displacement indicators often cannot represent the change of strength (stiffness) of the potential failure surface directly related to stability, thus causing some difficulties in the determination of changes in the rock block stability. In recent years, with the development of low-power and high-precision new technologies 


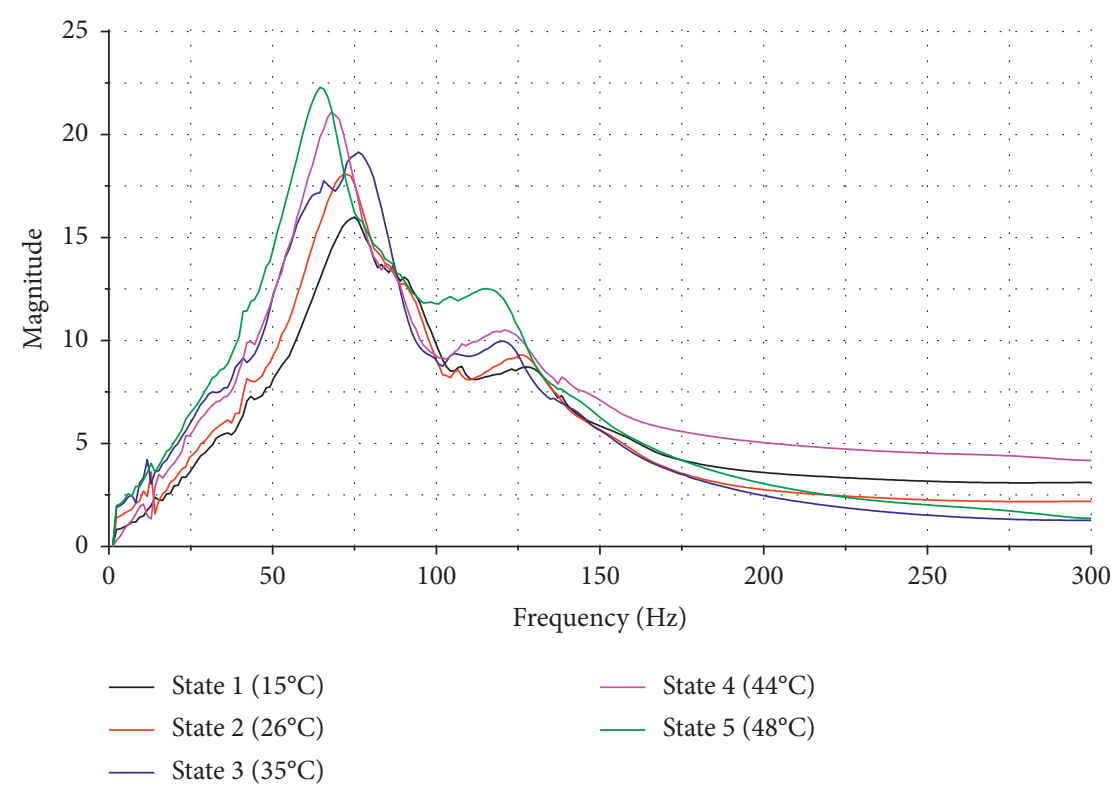

Figure 8: Typical spectrum curves of different states.

TABLE 2: The vibration feature parameters.

Feature

Mean frequency

Center frequency

Root mean square frequency

Peak frequency

Mean frequency standard deviation

where $s(k)$ is a spectrum for $k=1,2, \ldots, K, K$ is the number of spectrum lines, and $f_{k}$ is the frequency value of the $k$-th spectrum line.

TABLE 3: A list of vibration feature parameters and safety factors obtained experimentally.

\begin{tabular}{|c|c|c|c|c|c|c|c|c|c|c|c|}
\hline \multicolumn{12}{|c|}{ Vibration feature parameters } \\
\hline \multirow[t]{2}{*}{ State $\left( \pm 2^{\circ} \mathrm{C}\right)$} & \multicolumn{2}{|c|}{ P1 } & \multicolumn{2}{|c|}{$\mathrm{P} 2$} & \multicolumn{2}{|c|}{ P3 } & \multicolumn{2}{|c|}{$\mathrm{P} 4$} & \multicolumn{2}{|c|}{ P5 } & \multirow[t]{2}{*}{ Safety factor } \\
\hline & Data & Avg. & Data & Avg. & Data & Avg. & Data & Avg. & Data & Avg. & \\
\hline \multirow{3}{*}{$1\left(15^{\circ} \mathrm{C}\right)$} & 1.59 & \multirow{3}{*}{1.58} & 68.62 & \multirow{3}{*}{68.49} & 71.23 & \multirow{3}{*}{71.00} & 75.00 & \multirow{3}{*}{75.00} & 3.04 & \multirow{3}{*}{3.04} & \multirow{3}{*}{3.36} \\
\hline & 1.58 & & 68.37 & & 70.64 & & 75.00 & & 3.04 & & \\
\hline & 1.56 & & 68.48 & & 71.13 & & 75.00 & & 3.03 & & \\
\hline \multirow{3}{*}{$2\left(26^{\circ} \mathrm{C}\right)$} & 1.60 & \multirow{3}{*}{1.60} & 67.27 & \multirow{3}{*}{67.31} & 69.85 & \multirow{3}{*}{69.89} & 73.82 & \multirow{3}{*}{73.82} & 3.06 & \multirow{3}{*}{3.06} & \multirow{3}{*}{2.82} \\
\hline & 1.59 & & 67.38 & & 69.95 & & 73.82 & & 3.05 & & \\
\hline & 1.61 & & 67.29 & & 69.86 & & 73.82 & & 3.07 & & \\
\hline \multirow{3}{*}{$3\left(35^{\circ} \mathrm{C}\right)$} & 1.98 & \multirow{3}{*}{1.99} & 65.76 & \multirow{3}{*}{65.87} & 68.45 & \multirow{3}{*}{68.55} & 75.00 & \multirow{3}{*}{75.00} & 3.73 & \multirow{3}{*}{3.75} & \multirow{3}{*}{2.39} \\
\hline & 1.99 & & 66.11 & & 68.78 & & 75.00 & & 3.76 & & \\
\hline & 1.99 & & 65.73 & & 68.43 & & 75.00 & & 3.77 & & \\
\hline \multirow{3}{*}{$4\left(44^{\circ} \mathrm{C}\right)$} & 2.21 & \multirow{3}{*}{2.20} & 64.61 & \multirow{3}{*}{64.42} & 67.21 & \multirow{3}{*}{67.01} & 69.14 & \multirow{3}{*}{69.14} & 4.16 & & \\
\hline & 2.20 & & 64.54 & & 67.11 & & 69.14 & & 4.15 & 4.16 & 1.96 \\
\hline & 2.20 & & 64.13 & & 66.72 & & 69.14 & & 4.15 & & \\
\hline & 2.24 & & 62.69 & & 66.52 & & 64.45 & & 4.14 & & \\
\hline $5\left(48^{\circ} \mathrm{C}\right)$ & 2.26 & 2.25 & 62.76 & 62.71 & 65.56 & 65.53 & 64.45 & 64.45 & 4.14 & 4.14 & 1.45 \\
\hline & 2.26 & & 62.67 & & 65.50 & & 64.45 & & 4.15 & & \\
\hline $6\left(53^{\circ} \mathrm{C}\right)$ & & & & & & & & & & & $<1$ \\
\hline
\end{tabular}




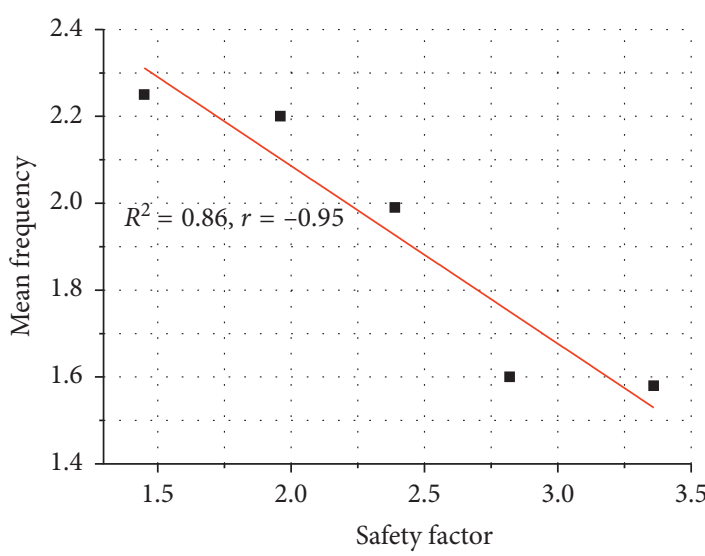

- P1

- Linear fit of P1

(a)

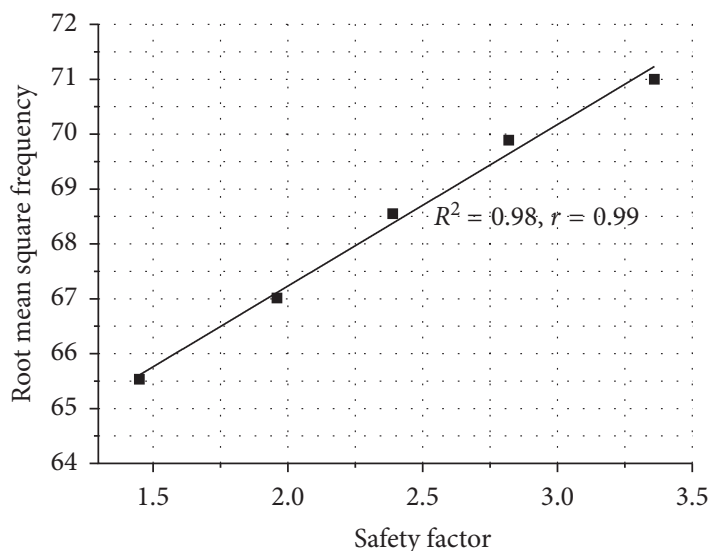

- $\mathrm{P} 3$

Linear fit of P3

(c)

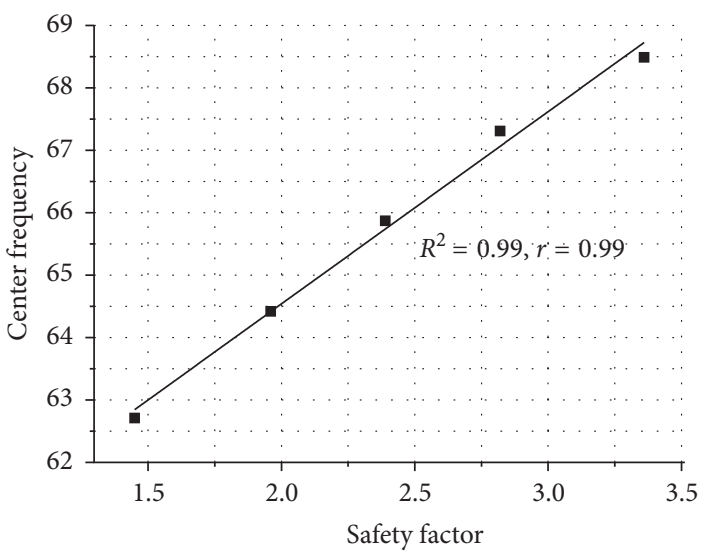

- $\mathrm{P} 2$

_ Linear fit of P2

(b)

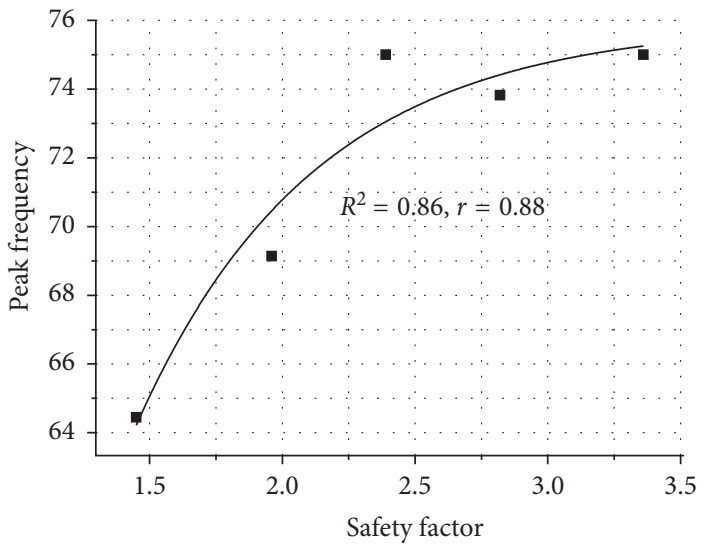

- P4

ExpDec1 fit of P4

(d)

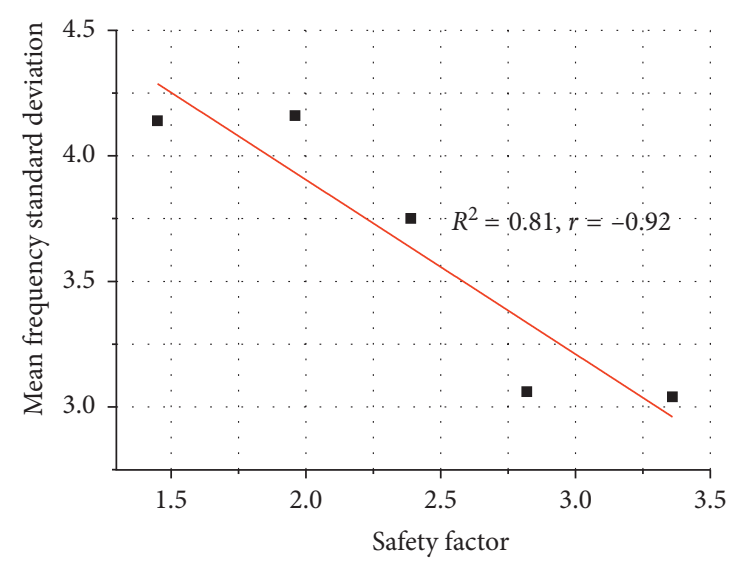

- P5

_ Linear fit of P5

(e)

Figure 9: Relation between the vibration feature parameters and the stability safety factor: (a) mean frequency and safety factor; (b) center frequency and safety factor; (c) root mean square frequency and safety factor; (d) peak frequency and safety factor; and (e) mean frequency standard deviation and safety factor. 


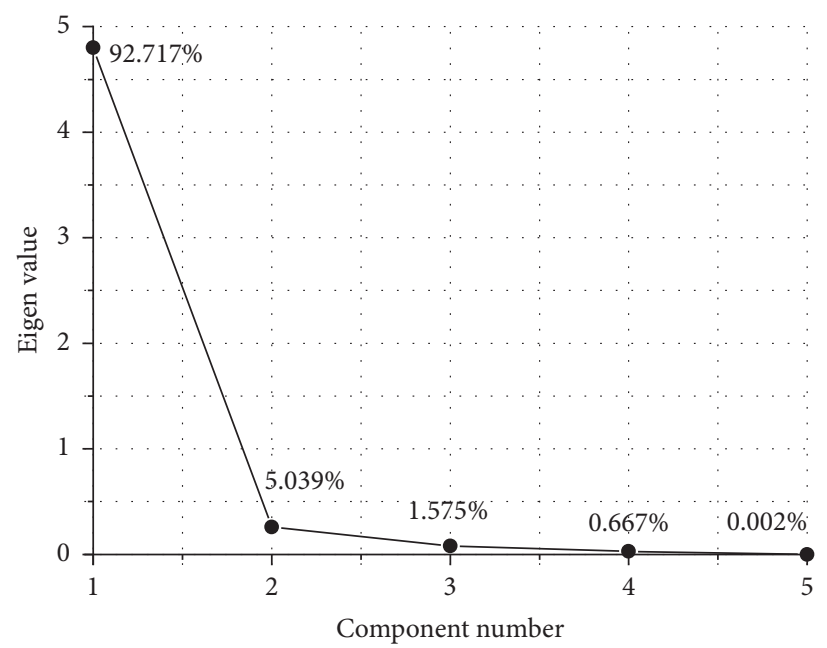

FIgURE 10: Scree plot of the principal component analysis.

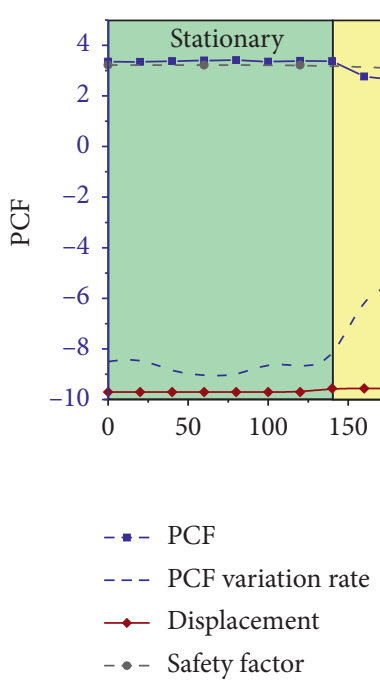

FIGURE 11: Behaviors of the safety factor, displacement, PCF, and PCF variation rate.

(microelectromechanical accelerometer, electromagnetic vibration exciter, LDV, etc.) [21, 30, 33], more studies are focusing on vibration feature parameters to monitor geotechnical slope. According to equation (3), there are quantitative relations between the natural frequency characteristics of rock blocks and their stiffness, while Figure 9 shows that there is a good correlation between five frequency-domain parameters and the safety factor of the rock block. Therefore, the five vibration feature parameters calculated by the equations in Table 2 can identify the decrease of rock block stability. From Figure 11, in the process of a rock block instability, the damage sensitivity of the comprehensive evaluation indicator PCF calculated by equation (7) is better than displacement, and the evolution of the PCF illustrates definite stages and instability precursor characteristics. Consequently, the monitoring of vibration feature parameters will provide a positive reference for the early warning of hazardous rock blocks in the future.

\section{Conclusions}

In this study, a fundamental physical model experiment is designed to explore the feasibility of using vibration feature parameters monitored by laser vibrometry to assess the stability of hazardous rock blocks on slopes.

The experimental results show that the stability safety factor of the block is negatively related to the mean frequency and the mean frequency standard deviation and positively related to the center frequency, the peak frequency and the root mean square frequency, which indicates that with decreasing block stability, the magnitude and constringency of the frequency domain increase, and the main frequencies gradually decrease. We also find that using a single vibration feature parameter to evaluate the stability may lead to misevaluation.

Furthermore, the principal component factor (PCF) of the vibration feature parameters has distinct stage characteristics, i.e., "stationary-deviation-acceleration," which can 
effectively characterize the stability evolution trend of the block, and its abnormal sudden drop in the acceleration stage is a precursor of collapse. In contrast, the displacement does not produce an obvious response before the block collapse. Thus, the damage sensitivity of the vibration feature parameters is better than that of the displacement. The monitoring of vibration feature parameters can provide a useful reference for the safety evaluation and early warning of a hazardous rock block on a slope.

\section{Data Availability}

The data used to support the findings of the study are included within the article.

\section{Conflicts of Interest}

The authors declare that they have no conflicts of interest.

\section{Acknowledgments}

The authors gratefully acknowledge the financial support from the National Key Research and Development Project of China (grant numbers 2018YFE0101100 and 2019YFC1509602).

\section{References}

[1] T. Oppikofer, M. Jaboyedoff, and H.-R. Keusen, "Collapse at the eastern eiger flank in the Swiss Alps," Nature Geoscience, vol. 1, no. 8, pp. 531-535, 2008.

[2] H.-K. Chen, H.-M. Tang, and S.-Q. Ye, "Damage model of control fissure in perilous rock," Applied Mathematics and Mechanics, vol. 27, no. 7, pp. 967-974, 2006.

[3] C. D. Martin, "Seventeenth Canadian geotechnical colloquium: the effect of cohesion loss and stress path on brittle rock strength," Canadian Geotechnical Journal, vol. 34, no. 5, pp. 698-725, 1997.

[4] H. R. Chen, S. Q. Qin, L. Xue, B. C. Yang, and K. Zhang, "A physical model predicting instability of rock slopes with locked segments along a potential slip surface," Engineering Geology, vol. 242, pp. 737-738, 2018.

[5] E. Eberhardt, D. Stead, and J. S. Coggan, "Numerical analysis of initiation and progressive failure in natural rock slopes-the 1991 Randa rockslide," International Journal of Rock Mechanics and Mining Sciences, vol. 41, no. 1, pp. 69-87, 2004.

[6] M. J. Royán, A. Abellán, and J. M. Vilaplana, "Progressive failure leading to the 3 December 2013 rockfall at Puigcercós scarp (Catalonia, Spain)," Landslides, vol. 12, no. 3, pp. 585-595, 2015.

[7] J. Zvelebill and M. Moser, "Monitoring based time-prediction of rock falls: three case-histories," Physics and Chemistry of the Earth, Part B: Hydrology, Oceans and Atmosphere, vol. 26, no. 2, pp. 159-167, 2001.

[8] G. B. Crosta and F. Agliardi, "Failure forecast for large rock slides by surface displacement measurements," Canadian Geotechnical Journal, vol. 40, no. 1, pp. 176-191, 2003.

[9] E. Intrieri, G. Gigli, F. Mugnai, R. Fanti, and N. Casagli, "Design and implementation of a landslide early warning system," Engineering Geology, vol. 147-148, pp. 124-136, 2012.

[10] R. A. Kromer, D. J. Hutchinson, M. J. Lato, D. Gauthier, and T. Edwards, "Identifying rock slope failure precursors using
LiDAR for transportation corridor hazard management," Engineering Geology, vol. 195, pp. 93-103, 2015.

[11] C. Atzeni, M. Barla, M. Pieraccini, and F. Antolini, "Early warning monitoring of natural and engineered slopes with ground-based synthetic-aperture radar," Rock Mechanics and Rock Engineering, vol. 48, no. 1, pp. 235-246, 2015.

[12] H. B. Li, X. G. Yang, H. L. Sun, S. C. Qi, and J. W. Zhou, "Monitoring of displacement evolution during the pre-failure stage of a rock block using ground-based radar interferometry," Landslides, vol. 16, no. 3, pp. 1721-1730, 2019.

[13] T. Carlà, T. Nolesini, L. Solari, C. Rivolta, L. Dei Cas, and N. Casagli, "Rockfall forecasting and risk management along a major transportation corridor in the Alps through groundbased radar interferometry," Landslides, vol. 16, no. 8, pp. 1425-1435, 2019.

[14] T. Carlà, P. Farina, E. Intrieri, K. Botsialas, and N. Casagli, "On the monitoring and early-warning of brittle slope failures in hard rock masses: examples from an open-pit mine," Engineering Geology, vol. 228, pp. 71-81, 2017.

[15] M. Janeras, J.-A. Jara, M. J. Royán et al., "Multi-technique approach to rockfall monitoring in the Montserrat massif (Catalonia, NE Spain)," Engineering Geology, vol. 219, pp. 4-20, 2017.

[16] Q. Sun, P. Chen, D. Zhang, and F. Xi, "Pattern recognition for automatic machinery fault diagnosis," Journal of Vibration and Acoustics, vol. 126, no. 2, pp. 307-316, 2004.

[17] K. Ogata, H. Matsuyama, and K. Amano, "Evaluation of the rockfall potential utilizing the characteristics of vibration," Doboku Gakkai Ronbunshu, vol. 749, no. 749, pp. 123-135, 2003, in Japanese.

[18] M. Kanda, N. Ugata, K. Arai, and H. Nakano, "Model and field tests for evaluating effect of mortar bonding by rock fall hazard rating system using characteristic of vibration," Journal of the Japan Landslide Society, vol. 44, no. 3, pp. 175-184, 2007, in Japanese.

[19] J. Burjánek, J. R. Moore, F. X. Yugsi Molina, and D. Fäh, "Instrumental evidence of normal mode rock slope vibration," Geophysical Journal International, vol. 188, no. 2, pp. 559-569, 2012.

[20] U. Kleinbrod, J. Burjánek, and D. Fäh, "On the seismic response of instable rock slopes based on ambient vibration recordings," Earth Planets and Space, vol. 69, no. 1, p. 126, 2017.

[21] H. H. Nasslf, M. Gindy, and J. Davis, "Comparison of laser doppler vibrometer with contact sensors for monitoring bridge deflection and vibration," NDT and E International, vol. 38, no. 3, pp. 213-218, 2005.

[22] K. S. Dai, Y. Wang, and Y. C. Hang, "Field testing of an inservice wind turbine tower using a laser based remote sensing method," Chinese Journal of Engineering, vol. 38, no. 10, pp. 1475-1481, 2016, in Chinese.

[23] G. C. Ma, K. Sawada, A. Yashima et al., "Experimental and numerical analysis of rock block stability using a remotely positioned laser doppler vibrometer," Journal of Civil Engineering and Architecture, vol. 8, no. 5, pp. 624-632, 2014.

[24] Y. Du, M. W. Xie, Y. J. Jiang, B. Li, and S. Chicas, "Experimental rock stability assessment using the Frozen-Thawing test," Rock Mechanics and Rock Engineering, vol. 50, no. 4, pp. 1-5, 2016.

[25] Y. C. Jia, M. W. Xie, S. X. Chang, and F. X. Lü, “A model for evaluation of stability of sliding- and falling-type dangerous rock blocks based on natural vibration frequency," Rock and Soil Mechanics, vol. 38, no. 7, pp. 2149-2156, 2017, in Chinese. 
[26] L. L. Chen, M. A. Gao, and S. G. Qian, "New theory of distinguishing slope stability-inherent frequency discrimination," Rock and Soil Mechanics, vol. 27, no. S, pp. 12191222, 2006, in Chinese.

[27] Y. Du, M. W. Xie, Y. J. Jiang, W. N. Liu, R. C. Liu, and Q. Q. Liu, "Research progress on dynamic monitoring index for early warning of rock collapse," Chinese Journal of Engineering, vol. 41, no. 4, pp. 427-435, 2019, in Chinese.

[28] S. Minoura, F. Uehan, and H. Saito, "Fundamental study on evaluating rock slope stability by vibration measurements using remote vibration measuring system," in Proceedings of the International Conference on Computational Methods in Structural Dynamics and Earthquake Engineering, pp. 34033414, Kos Island, Greece, June 2013.

[29] G. C. Ma, K. Sawada, A. Yashima, and H. Saito, "Experimental study of the applicability of the remotely positioned laser doppler vibrometer to rock-block stability assessment," Rock Mechanics and Rock Engineering, vol. 48, no. 2, pp. 787-802, 2015.

[30] M. W. Xie, Z. He, L. Liang, Z. X. Wu, and G. C. Sun, "Slope disaster monitoring and early warning system based on 3DMEMS and NB-IoT," in Proceedings of the 2019 IEEE 4th Advanced Information Technology, Electronic and Automation Control Conference (IAEAC), pp. 90-94, Chengdu, China, December 2019.

[31] Y. Y. Wang, X. Y. Fan, X. N. Gan, and J. G. Li, "Research and application of similarity theory for creep law under the action of temperature and pressure," Chinese Journal of Applied Mechanics, vol. 34, no. 6, pp. 1193-1199, 2017, in Chinese.

[32] Y. G. Lei, Z. J. He, Y. Y. Zi, and X. F. Chen, "New clustering algorithm-based fault diagnosis using compensation distance evaluation technique," Mechanical Systems and Signal Processing, vol. 22, no. 2, pp. 419-435, 2008.

[33] S. Tao, T. Uchimura, M. Fukuhara, J. F. Tang, Y. L. Chen, and D. Huang, "Evaluation of soil moisture and shear deformation based on compression wave velocities in a shallow slope surface layer," Sensors, vol. 19, no. 3406, pp. 1-15, 2019. 